\title{
Genetic Diversity of Panicum mosaic virus Satellite RNAs in St. Augustinegrass
}

\author{
Over Cabrera, Marilyn J. Roossinck, and Karen-Beth G. Scholthof
}

First and third authors: Department of Plant Pathology and Microbiology, Texas A\&M University, College Station 77843; second author:

The S. R. Noble Foundation, Inc., P.O. Box 2180, Ardmore, OK 73402.

Current address of O. Cabrera: Department of Biochemistry and Molecular Biology, Oklahoma State University, Stillwater 74078.

Accepted for publication 26 May 2000.

\begin{abstract}
Cabrera, O., Roossinck, M. J., and Scholthof, K.-B. G. 2000. Genetic diversity of Panicum mosaic virus satellite RNAs in St. Augustinegrass. Phytopathology 90:977-980.

St. Augustine decline is a viral disease caused by Panicum mosaic virus (PMV) alone or in combination with a satellite virus (SPMV) and/or satellite RNAs (satRNAs). A ribonuclease protection assay (RPA) was used to evaluate the genetic diversity of PMV satRNAs isolated from 100 naturally infected St. Augustinegrass plants (Stenotaphrum secundatum).

Distinctive satRNA RPA profiles were observed for 40 of 52 samples from College Station (CS) and 37 of 48 samples from Corpus Christi (CC), Texas. A dendrogram constructed from the RPA data revealed that satRNAs were grouped in two distinct clusters based on their place of origin. From 100 samples, only 4 satRNAs from CS were placed in the CC group, and only 2 satRNAs from CC were placed in the CS group. The data show that there is genetic variability in PMV satRNAs in naturally occurring infections, and distinct geographically separate populations can be identified from $\mathrm{CC}$ and $\mathrm{CS}$.
\end{abstract}

St. Augustine decline is a disease of viral etiology affecting St. Augustinegrass (Stenotaphrum secundatum (Walt.) Kuntze), a common turf grass in the Gulf Coast Region of the United States. The symptoms associated with this disease, ranging from a chlorotic mottle to bleached leaves, are incited by Panicum mosaic virus (PMV) (25), often in combination with a satellite virus (SPMV) $(6,32)$ and/or satellite RNAs (satRNAs) $(7,20)$. PMV, a 4,326-nt positive-sense single-stranded RNA virus (ssRNA) $(25,33)$, is the type member and, thus far, sole species in the Panicovirus genus within the family Tombusviridae (33). PMV has a narrow host range within the Poaceae. The genome of SPMV is a positive-sense ssRNA of 824 nt that encodes a $17.5-\mathrm{kDa}$ capsid protein. As a mixed infection with PMV, SPMV intensifies symptoms on millet, increases the PMV titer, and accelerates the rate of systemic spread (31). PMV satRNAs are $\approx 375$-nt ssRNA molecules that do not encode any proteins and depend on PMV for replication. PMV, SPMV, and the satRNAs do not share nucleotide sequence similarity, except for 7 and $3 \mathrm{nt}$ at the $5^{\prime}$ and $3^{\prime}$ termini, respectively (33). PMV satRNAs are usually associated with stunting in foxtail millet (Setaria italica (L.) P. Beauv. 'German Strain R'), an experimental host (O. Cabrera and K.-B. G. Scholthof, unpublished data). In other helper virus-satRNA systems, the satRNAs attenuate, enhance, or have no effect on symptoms induced by their helper viruses $(8,16,23,26,28)$. In St. Augustine decline, the role of PMV satRNAs in symptom modulation is unclear. However, $61 \%$ of symptomatic PMV-infected plants harbored satRNAs (7). Surveys at two locations in Texas, separated by $\approx 400 \mathrm{~km}$, revealed that, although symptoms could not be correlated with infections of PMV alone or in combination with the satellites, environmental conditions likely influenced the phenotype (7).

Understanding the genetic diversity of PMV satRNAs may help us understand how these molecular parasites evolve and their influence on the etiology of disease. Using the ribonuclease pro-

Corresponding author: K.-B. G. Scholthof; Email: kbgs@ acs.tamu.edu

Publication no. P-2000-0707-01R

(C) 2000 The American Phytopathological Society tection assay (RPA) and nucleotide sequencing for an extensive analyses of satellite tobacco mosaic virus (STMV), the heterogeneous nature of this satellite virus in wild populations of Nicotiana glauca L. was revealed (17). Similarly, Cucumber mosaic virus (CMV) satRNA populations also are highly diverse $(1,2)$. A common feature of CMV and PMV satRNAs is that their diversity in different regions may be influenced by climatic variations, such as temperature $(1,7)$.

In this study, we used RPA to analyze the diversity of 100 PMV satRNAs identified in our previous survey of 204 naturally infected St. Augustinegrass plants in College Station (CS) and Corpus Christi (CC), Texas (7). We found that there is a high degree of genetic variability in PMV satRNAs, and different, but overlapping, populations of PMV satRNAs were found in CS and CC.

\section{MATERIALS AND METHODS}

RPA. The RPA protocol was modified slightly from Kurath et al. (19) to make it compatible with RNase One (Promega Corp., Madison, WI) $(5,13)$. The minus-strand probe for the RPA was generated from a full-length cDNA clone of PMV satRNA-S1 with a reverse SP6 promoter at the $3^{\prime}$ terminus. The S1-3' End-SP6 construct was made by polymerase chain reaction amplification of the satRNA-S1 cDNA clone (20), with a $5^{\prime}$ primer $\left(5^{\prime}\right.$-GGGTATTCGTTGGGGCTTGC-3') representing the first $20 \mathrm{nt}$ of the satRNA genome, a $3^{\prime}$ primer (5'-ATTTAGGTGACACTATAGGGTGCTGCATACGCGAGCC-3') with complementarity to the $3^{\prime}$ end of the satRNA and an SP6 promoter sequence (underline), and subsequent ligation into the SmaI site of pUC119.

Minus-sense satRNA-S1 transcripts were synthesized in $25-\mu 1$ reactions containing $250 \mathrm{ng}$ of S1-3' End-SP6 (linearized with SmaI), $1 \times$ reaction buffer $(6 \mathrm{mM} \mathrm{MgCl} 2,2 \mathrm{mM}$ spermidine, $10 \mathrm{mM}$ dithiothreitol, $40 \mathrm{mM}$ Tris-HCl, $\mathrm{pH} 7.9$ ), $25 \mu \mathrm{Ci}$ of $\left[\alpha_{-}^{-}{ }^{32} \mathrm{P}\right] \mathrm{UTP}$ (Amersham, Piscataway, NJ), $100 \mu \mathrm{M}$ UTP, $1 \mathrm{mM}$ each ATP, CTP, and GTP, $20 \mathrm{U}$ of RNasin (Promega), and $10 \mathrm{U}$ of SP6 polymerase (New England Biolabs, Beverly, MA). After incubation for $1 \mathrm{~h}$ at $40^{\circ} \mathrm{C}, 2 \mathrm{U}$ of RQ1-DNase (Promega) was added, and the mix was incubated for $15 \mathrm{~min}$ at $37^{\circ} \mathrm{C}$. 
The satRNA transcripts were resolved on $1 \%$ agarose gels by electrophoresis in $1 \times$ TBE ( $90 \mathrm{mM}$ Tris-borate, $2 \mathrm{mM} \mathrm{Na} \mathrm{N}_{2}$ EDTA) (30). The band containing the minus-sense satRNA-S1 transcript was excised, and the RNA was eluted from the gel. The amount of radioactivity (counts per minute) incorporated was determined with a liquid scintillation analyzer (Packard Instrument Company, Meriden, CT) set to monitor the tritium window and count the Cerenkov radiation emitted from $1 \mu \mathrm{l}$ of sample without scintillation fluid.

Approximately $5 \mu \mathrm{g}$ of total nucleic acids extracted from St. Augustinegrass plants infected with satRNA was used for each assay (7). The concentration of satRNA from infected plants exceeded the concentration of the probe. The sample, together with $40,000 \mathrm{cpm}$ of probe, was ethanol precipitated, and after centrifugation, the pellet was resuspended in $30 \mu \mathrm{l}$ of annealing buffer (80\% deionized formamide, $400 \mathrm{mM}$ sodium acetate, $1 \mathrm{mM}$ $\mathrm{Na}_{2}$ EDTA, $40 \mathrm{mM}$ PIPES [piperazine- $N, N^{\prime}$-bis(2-ethanesulfonic acid)], $\mathrm{pH}$ 6.4). The nucleic acids were denatured at $95^{\circ} \mathrm{C}$ for $3 \mathrm{~min}$ and annealed overnight at $55^{\circ} \mathrm{C}$. RNase digestion buffer ( $5 \mathrm{mM} \mathrm{Na} \mathrm{m}_{2}$ EDTA, $200 \mathrm{mM}$ sodium acetate, $10 \mathrm{mM}$ Tris- $\mathrm{HCl}$, $\mathrm{pH}$ 7.5) containing $20 \mathrm{U}$ of RNase One, in a total volume of $300 \mu \mathrm{l}$, was added, and the reaction proceeded for $2 \mathrm{~h}$ at $25^{\circ} \mathrm{C}$. To degrade the RNase, $20 \mu \mathrm{g}$ of proteinase $\mathrm{K}$ was added, and the mixture was incubated at $37^{\circ} \mathrm{C}$ for $20 \mathrm{~min}$ prior to extraction with phenol/chloroform, precipitation in ethanol, and centrifugation. The resulting pellet was resuspended in $15 \mu \mathrm{l}$ of loading buffer (10 mM Na 2 EDTA, $80 \%$ deionized formamide, $0.01 \%$ bromophenol blue, $0.01 \%$ xylene cyanol, $0.1 \%$ sodium dodecyl sulfate) $(5,13)$.

The ribonuclease-insensitive dsRNA fragments were denatured at $90^{\circ} \mathrm{C}$ for $5 \mathrm{~min}$ and loaded on a $7 \%$ polyacrylamide/7 M urea gel (16 cm long and 20 lanes). Electrophoresis was performed in $1 \times$ TBE buffer at $50 \mathrm{~W}$ with constant power, and the gel was transferred to $0.35-\mathrm{mm}$ cellulose chromatography paper (Fisher Scientific, Pittsburgh) and dried in a gel dryer at $80^{\circ} \mathrm{C}$ for $2 \mathrm{~h}$. The fragments were detected by autoradiography on Kodak BioMax MR film (Eastman Kodak Company, Rochester, NY) after overnight exposure.

Estimation of genetic diversity by comparative analysis. Each satRNA was characterized by its RPA band pattern (profile). All fragments that were clearly present, regardless of their relative intensity, were recorded as a band (19). Each band was treated as a binary datum, and the profiles were converted to a binary matrix. Dice's metric, $S_{i j}=2 N_{11} /\left(2 N_{11}+N_{01}+N_{10}\right)$, was used to transform the binary matrix into a lower triangular similarity matrix $(9,24)$. In this equation, $i$ and $j$ represent any two samples, $N_{11}$ represents the number of bands shared by $i$ and $j, N_{10}$ represents the number of bands present in $i$ but not in $j$, and $N_{01}$ represents the number of bands present in $j$ but not in $i$. To represent the relationship among the satRNAs, a dendrogram was built using RAPDistance programs, 1.03 ed (RAPDistance is available online from the Bioinformatics Group, Research School of Biological Sciences, Canberra, Australia), the Neighbor-Joining algorithm (29) and the similarity matrix.

\section{RESULTS}

RPA was utilized in this study to detect the genetic variability of satRNAs isolated from naturally infected St. Augustinegrass. RPA provides a rapid and sensitive analysis of nucleotide differences in RNA samples $(4,22,27,34)$ and, as such, is suited for estimating the variation within satRNA samples. Differences in the banding patterns of cleavage fragments between target RNAs can be used as markers to appraise genetic diversity $(14,19)$. This evaluation most likely under-represents the true diversity, because most RPA systems detect only a fraction of the mismatches $(19,22)$, but it is suitable for a preliminary screening of many field samples (3).
Representative RPA banding patterns of samples from CS and $\mathrm{CC}$ are shown in Figure 1. Because RPA is subject to possible artifacts, control samples were used to monitor the performance and reproducibility of the experimental conditions (Fig. 1A and B, lanes $1,2,3$, and 20, labeled $\mathrm{C} 1$ through $\mathrm{C} 4$, respectively), and a RNA ladder was used to estimate the sizes of the fragments. One control (Fig. 1, C1) contained the total nucleic acids isolated from a millet plant infected with PMV and SPMV. A second control (Fig. 1, C2) contained the total nucleic acids isolated from a plant infected with PMV, SPMV, and satRNA-S1. As expected, the majority of the probe was protected, resulting in an intact band near the top of the gel due to the perfect complementarity between the probe and satRNA in this control. The faint band at $175 \mathrm{nt}$ and the slightly higher molecular weight smear in C2 are probably due to duplex "breathing," which allows the ribonucleases to attack certain residues in double-stranded regions, a drawback inherent to the RPA technique (19). Control 3 (Fig. 1, C3) contains PMV satRNA-C4, a template with a known sequence slightly different from satRNA-S1, which allowed us to monitor the reproducibility of each assay. The profile of satRNA-C4 was consistent throughout the assays (Fig. 1). Control 4 is the undigested probe (Fig. 1, C4) used to confirm that no degradation, in the absence of RNase, occurred during the experiments.

RPA profiles of 30 representative samples collected from either CS (Fig. 1A, lanes 4 through 9 and 11 through 19) or CC (Fig. 1B, lanes 4 through 9 and 11 through 19) revealed many distinct but related RPA profiles. For example, RPAs of satRNAs from CS contained a high molecular weight band (a) that was absent in the CC samples (Fig. 1A). A low molecular weight band (b) was common to samples from both locations, and a third band (c) was more prevalent in the CC samples compared with the CS samples (Fig. 1A and B). These bands suggest that satRNA populations in $\mathrm{CS}$ and $\mathrm{CC}$ differ in nucleotide sequence.

A total of 40 profiles was observed for the 52 samples collected from CS. Unique RPA profiles were observed for 33 individual samples (63\%), and the remaining 19 samples were grouped in 7 additional characteristic profiles. For example, samples 6 and 10 were grouped as a distinctive profile type, and samples 13, 14, 17, and 18 represented another profile type (Fig. 1A). Of the 48 samples collected in CC, $31(66 \%)$ had unique satRNA profiles, and the remaining 17 samples grouped in 6 additional distinctive profiles (Fig. 1B). These data indicate genetic variability exists among PMV satRNAs infecting St. Augustinegrass, both within and between locations. However, the number of different profiles observed in each of the individual locations suggests a similar level of genetic diversity within each population.

A dendrogram was constructed based on a binary matrix for the presence or absence of each band in the RPA profile to depict similarity relationships (29). The satRNAs mostly grouped according to their respective collection site, CS or CC (Fig. 2). Only four satRNAs from CS (samples 80, 82, 84, and 101) were placed in the CC group, and only two satRNAs from CC (samples 172 and 173) were placed in the CS group (Fig. 2, outlying samples are indicated by an asterisk). Within each group (CS or CC), there was no absolute correlation between the proximity (geographic distance) of a sampled plant and the position of the satRNA sample on the dendrogram (Fig. 2). However, samples collected from plants at proximal sites did tend to occupy closer positions on the dendrogram. For example, in the CS cluster samples 92, 93, and 94 were collected from nearby sites, and they grouped together in the dendrogram, but samples 31,34 , and 35 were collected from adjoining yards, and they were positioned in completely different branches in the dendrogram (Fig. 2). A similar situation was observed for CC samples 142 to 144 and 146, which were collected from lawns in close proximity. Samples 143, 144, and 146 had identical RPA profiles, but sample 142 had a unique RPA profile and was positioned on a different branch in the dendrogram (Fig. 2). 


\section{DISCUSSION}

The RPA technique is suitable for rapid analysis of RNA diversity in large samples (27). Its implementation in this study illustrated the genetic diversity of 100 PMV satRNA samples collected from two locations in Texas separated by $400 \mathrm{~km}$ (Figs. 1 and 2). The samples previously were confirmed to contain PMV satRNAs by an RNA blot assay (7).

The source of RNA used was total plant nucleic acids extracted from St. Augustinegrass plants in lawns and urban recreation fields infected with PMV and its satellites, based on an earlier study (7). This collection and extraction strategy avoided changes to the satRNA populations that may occur during the maintenance of samples in the greenhouse or inoculum passage to different host plants (21). Therefore, the variability reported here is representative of a PMV satRNA population under natural field conditions. Because RNA viruses and their satRNAs exist as heterogeneous populations in a single infection $(10-12,18,19)$, the pattern of satRNA variability derived from the RPA reflects the consensus of the heterogeneity that may exist in individual PMV satRNA infections. In other words, RPA provides a "snapshot" of the consensus profile in individual PMV satRNA infections of St. Augustinegrass.

For RPA, a full-length cDNA clone of PMV satRNA-S1 (20) was used to generate a minus-strand radiolabeled probe. The choice of probe is critical, because too much or too little similarity between the probe and template can impede the estimation of the variability in a population $(1,15)$. In addition, RNase One, instead of RNase A or a mixture of RNases A and T1, was used for RPA.
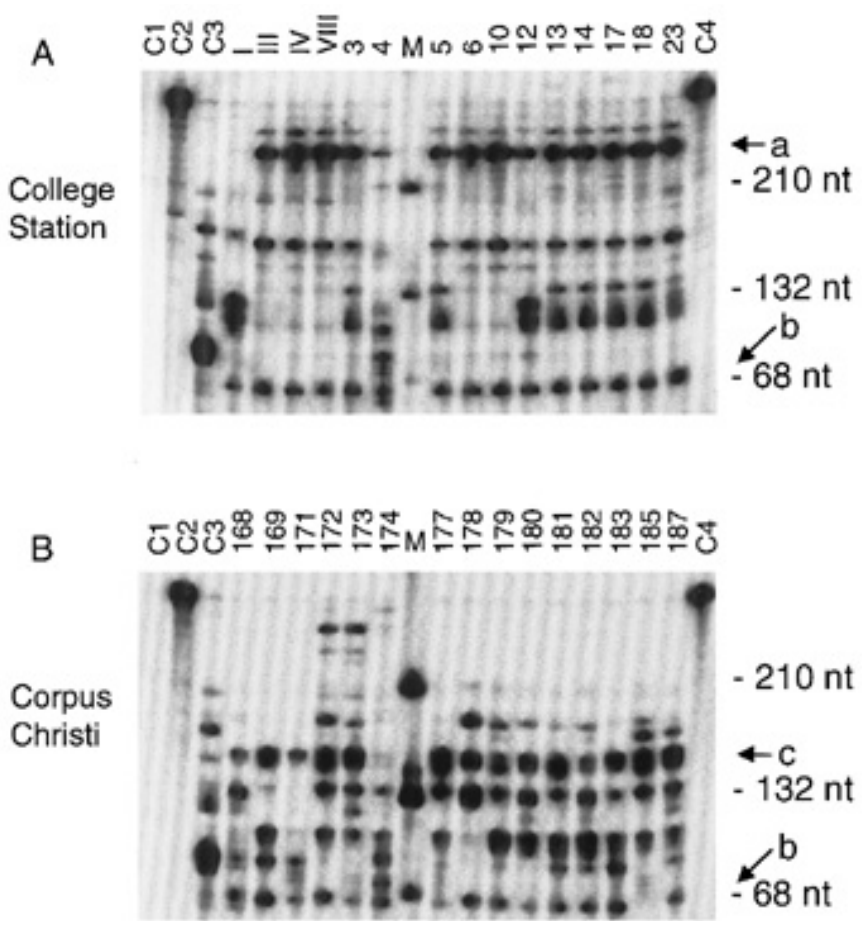

Fig. 1. Ribonuclease protection assay (RPA) of 30 representative Panicum mosaic virus (PMV) satRNAs. St. Augustinegrass sample collection numbers from A, College Station (CS) and B, Corpus Christi (CC), TX, are indicated above each lane. A ${ }^{32} \mathrm{P}$-labeled satRNA-S1 minus-sense transcript was used as the RPA probe for each sample and control. Four controls (C1 through $\mathrm{C} 4)$ and an RNA ladder (M) are included in each gel. Lane C1, probe plus total nucleic acids from a foxtail millet plant (Setaria italica 'German Strain R') infected with PMV and its satellite virus (SPMV), but lacking satRNAs; lane $\mathrm{C} 2$, probe plus total nucleic acids from millet infected with PMV, SPMV, and satRNA-S1; lane C3, probe plus satRNA-C4, a PMV satRNA with known sequence variability from satRNA-S1; and lane C4, probe alone without RNase. Arrows indicate RPA bands highly conserved for only CS PMV satRNAs (a), bands conserved for both CS and CC satRNAs (b), and a band more prevalent in CC-derived satRNAs (c). The size of each RNA marker band (M; center lanes) is indicated to the right of each panel.
Unlike RNases A and T1, RNase One cleaves phosphodiester bonds between all unpaired ribonucleotides (5) and, therefore, potentially can detect more mismatches between the sample and probe and generate more robust analysis of the diversity of PMV satRNAs.

The PMV satRNA RPA profiles were analyzed only qualitatively (discussed earlier). The presence or absence of a band was the only datum taken into account, because it is not possible to resolve whether an RPA band is the result of partial or complete digestion. Therefore, absolute distances were not determined, because they might have given a misleading conclusion about how evolutionarily distant one satRNA was from another. The dendrogram created provides a graphic representation of the relationship (similarity) among the satRNAs, but it does not depict phylogenetic relationships (i.e., relationships based on descent or ancestry) among them (Fig. 2). The distance values used to build the dendrogram were interpreted as a proportion of the distances among all the satRNAs analyzed, not the absolute value of such distances. This allows interpretation of the relative (or proportionate) closeness of two samples, although not in terms of temporal (evolutionary) distance. The dendrogram representing these profiles indicates that diverse satRNA profiles exist within and between the two locations.

We found that the satRNA samples separated into two clearly distinct clusters (Fig. 2) corresponding to the two locations, suggesting that these clusters may represent distinct populations that either have been evolving independently for some time or are subject to different selection pressures at either location. Although the only known transmission of PMV and its satellites is mechanical, including lawn mowers and turf replacement with infected sod or sprigs, this may provide enough gene flow between the two relatively isolated St. Augustinegrass populations to account for the minor cross-contamination of CC and CS samples (Fig. 2).

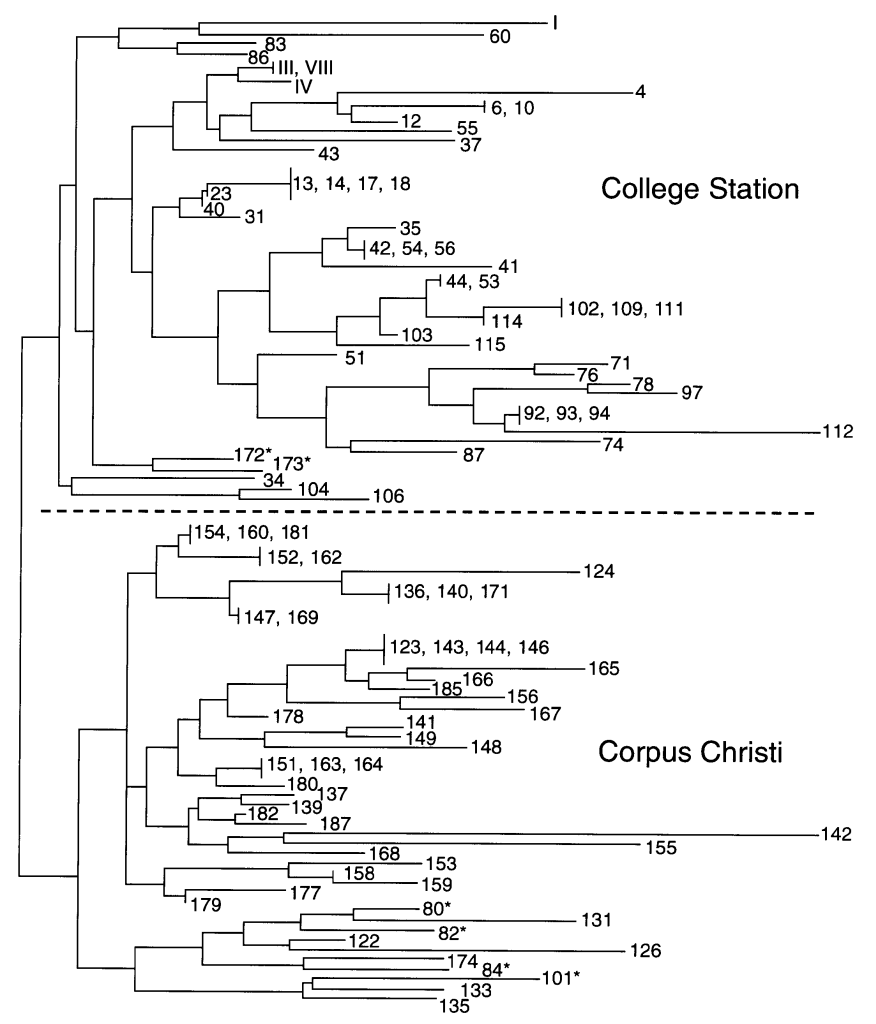

Fig. 2. Dendrogram depicting similarities among 100 Panicum mosaic virus satRNAs revealed by ribonuclease protection assays. Numbers indicate individual St. Augustinegrass plants harboring satRNAs. Samples with numbers less than 120 were collected at College Station (CS), TX; sample numbers greater than 120 were collected from Corpus Christi (CC), TX. A dotted horizontal line separates the CS and CC samples, except for numbers followed by an asterisk, which indicate satRNAs that grouped outside the samples from their respective collection sites. 
We also found that significant genetic variability exists within each cluster. The distinct number of profiles of PMV satRNAs was high but similar at both collection sites (i.e., 40 in CS and 37 in $\mathrm{CC}$ ). The genetic diversity of PMV satRNA may reflect the average number of consensus PMV satRNA profiles that can coexist when the system has been evolving for a long period of time under similar selection pressure. It is necessary to reiterate that RPA detects only a fraction of the actual differences; thus, these numbers may be higher after sequence analyses of the satRNAs. However, the robustness of RPA data for predicting genetic variability has been shown for STMV and CMV satRNAs. For example, analysis of STMV isolates collected from naturally infected $N$. glauca revealed that 10 of 15 isolates had distinct RPA profiles (17). In another RPA study (2), the proportion of CMV satRNA with distinct profiles (60 of 62 analyzed) was considerably higher than was observed for PMV satRNA.

These data suggest that different selection pressures may exist for satRNAs on annual versus perennial host plants. For example, CMV satRNA populations appear to undergo dynamic evolution every year $(2,15)$, probably due to annual cropping practices for tomatoes, decrease of aphid populations during the fall, and overwintering in alternate host plants. The CMV satRNAs are under constant evolutionary pressure, which could result in CMV satRNAs continuously evolving to adapt to new hosts and aphid vectors. Satellites in perennial hosts, such as PMV and its satellites in grasses or STMV in N. glauca, might be subjected to less evolutionary pressure.

At this point, we know that PMV satRNAs, like many RNA viruses, possess high genetic variability. However, the role of PMV satRNAs in St. Augustine decline disease remains unclear. The results of this study indicate that two essentially isolated PMV satRNA populations exist in PMV-infected St. Augustinegrass in CS and CC. It would be interesting to determine whether other geographically separate PMV satRNA variants can be identified and whether a geographic location exists with overlap of the CC and CS satRNA populations. Further study of satRNAs populations extending on a north-south axis in Texas or a sampling along the coast of the Gulf of Mexico, from Texas to Florida, also may help in deciphering the evolution of these satRNAs.

\section{ACKNOWLEDGMENTS}

This research was supported by USDA-NRI Competitive Grant 9635303-3714 (K.-B. G. Scholthof), the Texas Agricultural Experiment Station H-8388 (K.-B. G. Scholthof), and the S. R. Noble Foundation. We thank H. Scholthof, M. A. Hussey, G. Kurath, and J. Rodrigues de Miranda for providing many helpful discussions. We also thank H. Scholthof, G. Kurath, F. García-Arenal, and W. Qiu for comments and suggestions on the manuscript.

\section{LITERATURE CITED}

1. Alonso-Prados, J. L., Aranda, M. A., Malpica, J. M., García-Arenal, F., and Fraile, A. 1998. Satellite RNA of cucumber mosaic cucumovirus spreads epidemically in natural populations of its helper virus. Phytopathology 88:520-524.

2. Aranda, M. A., Fraile, A., and García-Arenal, F. 1993. Genetic variability and evolution of the satellite RNA of cucumber mosaic virus during natural epidemics. J. Virol. 67:5896-5901

3. Aranda, M. A., Fraile, A., García-Arenal, F., and Malpica, J. M. 1995. Experimental evaluation of the ribonuclease protection assay method for the assessment of genetic heterogeneity in populations of RNA viruses. Arch. Virol. 140:1373-1383.

4. Arens, M. 1999. Methods for subtyping and molecular comparison of human viral genomes. Clin. Microb. Rev. 12:612-626.

5. Brewer, G., Murray, E., and Staeben, M. 1992. RNase One: Advantages for nuclease protection assays. Promega Notes 38:1.

6. Buzen, F. G., Niblett, C. L., Hooper, G. R., Hubbard, J., and Newman, M. A. 1984. Further characterization of panicum mosaic virus and its associated satellite virus. Phytopathology 74:313-318.

7. Cabrera, O., and Scholthof, K.-B. G. 1999. The complex viral etiology of St. Augustine decline. Plant Dis. 83:902-904.

8. Celix, A., Rodriguez-Cerezo, E., and García-Arenal, F. 1997. New satellite RNAs, but no DI RNAs, are found in natural populations of tomato bushy stunt tombusvirus. Virology 239:277-284.

9. Dice, L. R. 1945. Measures of the amount of ecologic association between species. Ecology 26:297-302.

10. Domingo, E., Martínez-Salas, E., Sobrino, F., de la Torre, J. C., Portela, A., Ortin, J., López-Galíndez, C., Pérez-Brena, P., Villanueva, N., Najera, R., Van de Pol, S., Steinhauer, D., DePolo, N., and Holland, J. J. 1985. The quasispecies (extremely heterogeneous) nature of viral RNA genome populations: Biological relevance-A review. Gene 40:1-8.

11. Eigen, M. 1993. Viral quasispecies. Sci. Am. 269:42-49.

12. Eigen, M. 1996. On the nature of virus quasispecies. Trends Microbiol. 4:216-218.

13. Ekenberg, S., and Hudson, G. 1994. RNase protection assay system: A versatile technique for the analysis of RNA. Promega Notes 46:14.

14. Fraile, A., Malpica, J. M., Aranda, M. A., Rodriguez-Cerezo, E., and García-Arenal, F. 1996. Genetic diversity in tobacco mild green mosaic tobamovirus infecting the wild plant Nicotiana glauca. Virology 223: $148-155$.

15. Grieco, F., Lanave, C., and Gallitelli, D. 1997. Evolutionary dynamics of cucumber mosaic virus satellite RNA during natural epidemics in Italy. Virology 229:166-174.

16. Kong, Q. Z., Oh, J. W., and Simon, A. E. 1995. Symptom attenuation by a normally virulent satellite RNA of turnip crinkle virus is associated with the coat protein open reading frame. Plant Cell 7:1625-1634.

17. Kurath, G., Heick, J. A., and Dodds, J. A. 1993. RNase protection analyses show high genetic diversity among field isolates of satellite tobacco mosaic virus. Virology 194:414-418.

18. Kurath, G., and Palukaitis, P. 1989. RNA sequence heterogeneity in natural populations of three satellite RNAs of cucumber mosaic virus. Virology 173:231-240.

19. Kurath, G., Rey, M. E. C., and Dodds, J. A. 1992. Analysis of genetic heterogeneity within the type strain of satellite tobacco mosaic virus reveals several variants and a strong bias for $\mathrm{G}$ to A substitution mutations. Virology 189:233-244.

20. Monis, J., Sopher, D. S., and Jackson, A. O. 1992. Biologically active cDNA clones of panicum mosaic virus satellites. (Abstr.) Phytopathology $82: 1175$.

21. Moriones, E., Fraile, A., and García-Arenal, F. 1991. Host-associated selection of sequence variants from a satellite RNA of cucumber mosaic virus. Virology 184:465-468.

22. Myers, R. M., Larin, Z., and Maniatis, T. 1985. Detection of single base substitutions by ribonuclease cleavage at mismatches in RNA:DNA duplexes. Science 230:1242-1246.

23. Naidu, R. A., Collins, G. B., and Ghabrial, S. A. 1991. Symptom modulating properties of peanut stunt virus satellite RNA sequence variants. Mol. Plant-Microbe Interact. 4:268-275.

24. Nei, M., and Li, W. H. 1979. Mathematical model for studying genetic variation in terms of restriction endonucleases. Proc. Natl. Acad. Sci. 76: 5269-5273.

25. Niblett, C. L., and Paulsen, A. Q. 1975. Purification and further characterization of panicum mosaic virus. Phytopathology 65:1157-1160.

26. Palukaitis, P., and Roossinck, M. J. 1996. Spontaneous change of a benign satellite RNA of cucumber mosaic virus to a pathogenic variant. Nature Biotechnol. 14:1264-1268.

27. Palukaitis, P., Roossinck, M. J., and García-Arenal, F. 1994. Applications of ribonuclease protection assay in plant virology. Methods Mol. Genet. 4:237-250.

28. Roossinck, M. J., Sleat, D., and Palukaitis, P. 1992. Satellite RNAs of plant viruses: Structures and biological effects. Microbiol. Rev. 56:265-279.

29. Saitou, N., and Nei, M. 1987. The neighbor-joining method: A new method for reconstructing phylogenetic trees. Mol. Biol. Evol. 4:406-425.

30. Sambrook, J., Fritsch, E. F., and Maniatis, T. 1989. Molecular Cloning: A Laboratory Manual. Cold Spring Harbor Laboratory Press, Cold Spring Harbor, NY.

31. Scholthof, K.-B. G. 1999. A synergism induced by satellite panicum mosaic virus. Mol. Plant-Microbe Interact. 12:163-166.

32. Scholthof, K.-B. G., Jones, R. W., and Jackson, A. O. 1999. Biology and structure of plant satellite viruses activated by icosahedral helper viruses. Curr. Top. Microbiol. Immunol. 239:123-143.

33. Turina, M., Maruoka, M., Monis, J., Jackson, A. O., and Scholthof, K.B. G. 1998. Nucleotide sequence and infectivity of a full-length cDNA clone of panicum mosaic virus. Virology 241:141-155.

34. Winter, E., Yamamoto, F., Almoguera, C., and Perucho, M. 1985. A method to detect and characterize point mutations in transcribed genes: Amplification and overexpression of the mutant c-Ki-ras allele in human tumor cells. Proc. Natl. Acad. Sci. USA 82:7575-7579. 